\title{
JAVA ANDROID UNTUK SARANA INFORMASI \\ LABORATORIUM KOMPUTASI DAN SISTEM INFORMASI
}

Oleh :

DWI PUTRO SARWO SETYOHADI *)

\begin{abstract}
ABSTRAK
Laboratorium sebagai sarana belajar vokasi pada lingkungan politeknik khususnya jurusan teknologi informasi menjadi motor utama dalam kegiatan belajar mengajar. Tidak dipungkiri hampir seluruh aktivitas mahasiswa adalah praktikum yang berada di dalam laboratorium. Peran dan kesiapan laboratorium itu sendiri didalam memberikan pelayanan prima kepada customer nya adalah prioritas. Jadwal penggunaan laboratorium yang padat, teknisi yang bertugas, serta informasi lain yang berhubungan dengan Laboratorium sangatlah dibutuhkan.

Informasi yang didukung mobilitas akses sangatlah prior dan kunci sukses untuk menjawab tantangan di atas. Perkembangan teknologi komunikasi dilebur beserta kemampuan sistem operasi yang rendah resource, multi platform, dan memiliki endurance yang baik menjadi sarana yang digunakan untuk menyediakan informasi yang mudah dan fleksibel. Pada penelitian ini dibuat agar dapat diaksesnya informasi tersebut dengan menggunakan piranti mobile dengan sistem operasi Android dengan Java Platform.
\end{abstract}

Kata Kunci : Sistem Operasi Android, Java Platform 


\section{I.PENDAHULUAN}

Teknologi dalam kehidupan masyarakat sudah bukan hal asing, ini dibuktikan dengan banyaknya teknologi yang dibuat untuk membantu mempermudah dan meringankan kehidupan manusia. Diantaranya adalah perkembangan teknologi komunikasi. Perubahan dari penggunaan kertas sebagai sarana menuliskan informasi, sekarang sudah banyak model sarana yang bisa dipergunakan. Dari yang berupa sms (short message services), email, koran elektrik (e-news), $W e b$, dan masih banyak model lagi.

Laboratorium Komputasi dan Sistem Informasi sebagai salah satu jantung dari ekosistem Jurusan Teknologi Informasi, memiliki load yang sangat tinggi. Jam operasional laboratorium itu sendiri bisa mencapai 20 jam per hari, baik untuk kepentingan perkuliahan, penelitian, dan pengujian Tugas Akhir. Hal ini mengindikasikan lalu lalang informasi yang ada di dalamnya adalah sangat padat, baik jadwal penggunaan, jadwal kerja para teknisi, dan informasi-informasi lain yang lebih teknis, semisal jadwal maintenance laboratorium itu sendiri.

Banyaknya pengguna laboratorium, dan padatnya jadual laboratorium menjadi hal yang sangat diprioritaskan. Juga adanya perubahan jadual matakuliah yang menggunakan laboratorium serta peminjaman laboratorium untuk keperluan penelitaian atau pelatihan pelatihan mengakibatkan kebutuhan akan adanya informasi yang mudah didapat dan diakses adalah prior dan mendesak.

\section{TINJAUAN PUSTAKA}

Dalam pembuatan aplikasi mobile informasi berbasis Android, penulis mempunyai beberapa dasar teori yang digunakan, dasar teori inilah yang nantinya dapat dijadikan landasan ilmu dalam merancang dan membuat aplikasi mobile.

A. Android

Android adalah sistem operasi untuk telepon seluler yang berbasis linux yang mencakup sistem operasi, middleware, dan aplikasi. Android menyediakan platform terbuka bagi para pengembang untuk menciptakan aplikasi mereka. Awalnya, Google Inc. membeli Android Inc. yang merupakan pendatang baru yang membuat peranti lunak untuk telepon seluler. Kemudian untuk mengembangkan Android, dibentuklah Open Handset Alliance, konsorsium dari 34 perusahaan peranti keras, peranti lunak, dan telekomunikasi, termasuk Google, HTC, Intel, Motorola, Qualcomm, T-Mobile, dan Nvidia (Safaat, 2011: 1) B. Unified Modelling Language (UML)
Unified Modelling Language (UML) adalah sebuah "bahasa" yang telah menjadi standar dalam industri untuk visualisasi, merancang dan mendokumentasikan sistem piranti lunak. UML menawarkan sebuah standar untuk merancang model sebuah sistem. Tetapi karena UML juga menggunakan class dan operation dalam konsep dasarnya, maka ia lebih cocok untuk penulisan piranti lunak dalam bahasa berorientasi objek seperti C++, Java, C\# atau VB.NET. Walaupun demikian, UML tetap dapat digunakan untuk modeling aplikasi prosedural dalam VB atau C (Dharwiyanti dan Warhono, 2003: 2).

C. Use Case Diagram

Use case diagram dapat sangat membantu bila kita sedang menyusun requirement sebuah sistem, mengkomunikasikan rancangan dengan klien, dan merancang test case untuk semua feature yang ada pada sistem. (Dharwiyanti dan Warhono, 2003: 4).

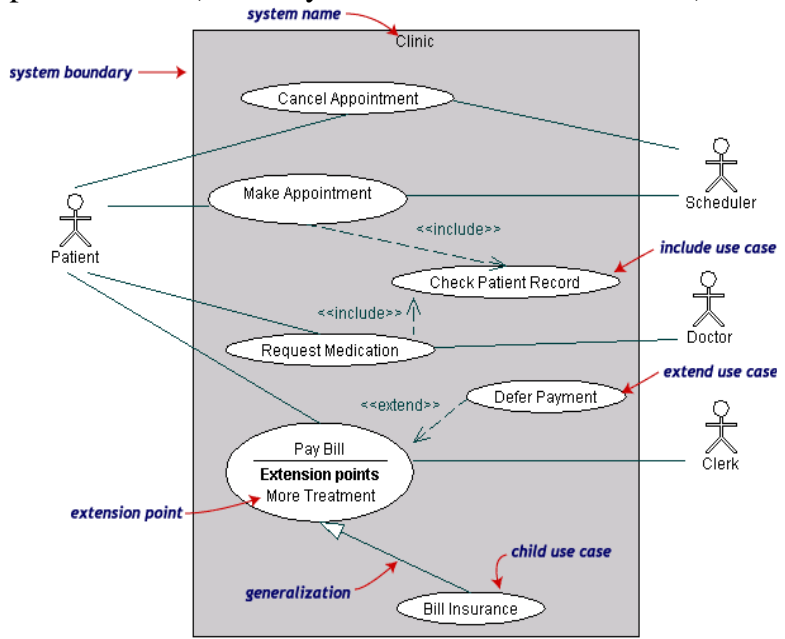

Gambar 1. Use Case Diagram

D. Activity Diagram

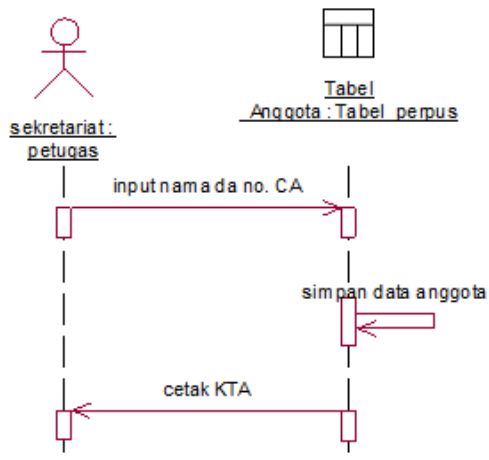

Gambar 2. Sequence Diagram

Activity diagram merupakan state diagram khusus, di mana sebagian besar state adalah action dan sebagian besar transisi di-trigger oleh selesainya state sebelumnya (internal processing). Oleh karena itu activity diagram tidak menggambarkan behaviour internal 
Dwi Putro S, Java Android Untuk Sarana Informasi Laboratorium Komputasi Dan Sistem Informasi

sebuah sistem (dan interaksi antar subsistem) secara eksak, tetapi lebih menggambarkan proses-proses dan jalur-jalur aktivitas dari level atas secara umum (Dharwiyanti dan Warhono, 2003: 7).

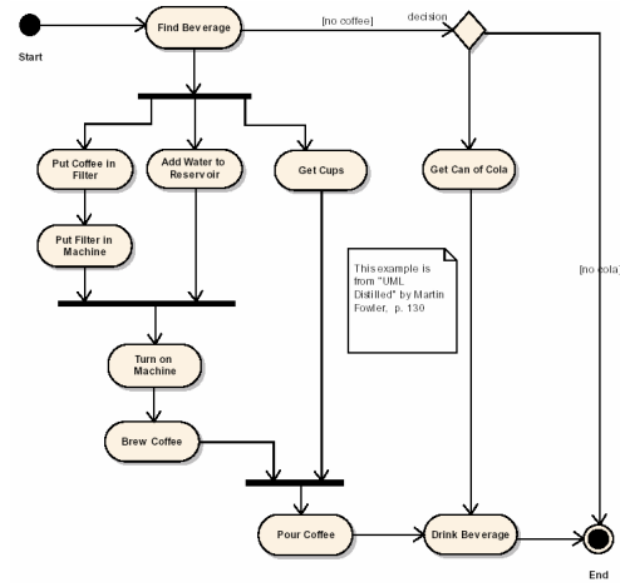

Gambar 3. Activity Diagram

\section{E. Statechart Diagram}

Dalam UML, state digambarkan berbentuk segiempat dengan sudut membulat dan memiliki nama sesuai kondisinya saat itu. Transisi antar state umumnya memiliki kondisi guard yang merupakan syarat terjadinya transisi yang bersangkutan, dituliskan dalam kurung siku. Action yang dilakukan sebagai akibat dari event tertentu dituliskan dengan diawali garis miring. Titik awal dan akhir digambarkan berbentuk lingkaran berwarna penuh dan berwarna setengah (Dharwiyanti dan Warhono, 2003: 7).

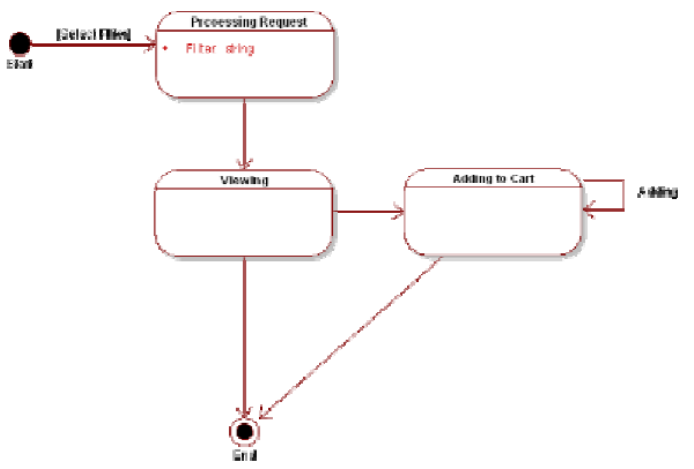

Gambar 4. Statechart Diagram

F. Java

Java adalah bahasa dan platform berasal oleh

Sun

Microsystems.

Bagian

ini menggambarkan bahwa bahasa ini menjelaskan apa artinya Java menjadi platform. Untuk memenuhi berbagai kebutuhan, Sun menyelenggarakan Java ke dalam tiga edisi utama, Java SE, Java EE, dan Java ME. Bagian ini juga sempat mengeksplorasi masing-masing edisi, bersama dengan Android. ( Friesen, 2010: 1 )

\section{METODA PENELITIAN}

Dalam pengembangan sebuah sistem, penulis menggunakan model pengembangan air terjun atau waterfall yang dibuat oleh Royce (Sommerrville, 2003: 43).

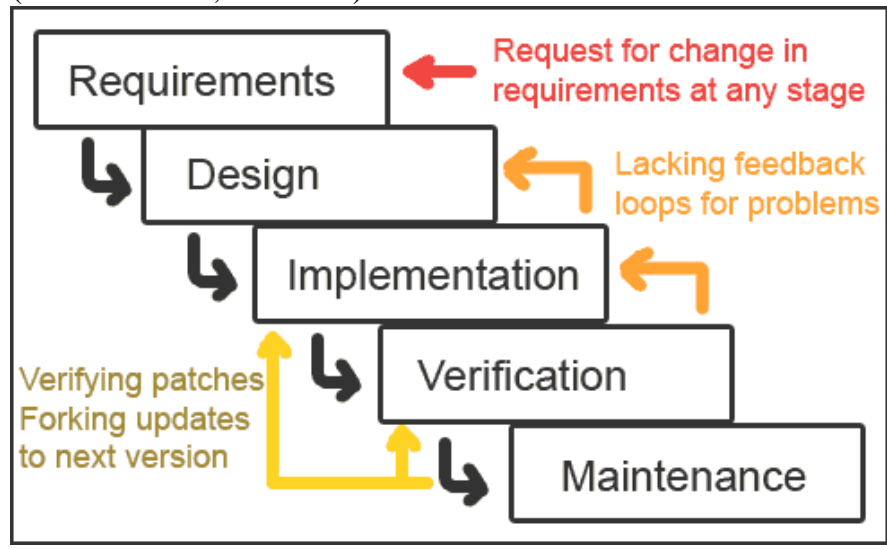

Gambar 5. Metoda Waterfall

Sesuai dengan model pengembangan yang telah dibuat maka selanjutnya penulis akan mengerjakan sesuai dengan tahap-tahapan tersebut.

\section{A. Requirements}

Penulis dalam tahapan ini melakukan data mining terhadap pembuatan aplikasi ini. Aplikasi ini akan menampilkan informasi dasar tentang Laboratorium Komputasi dan Sistem Informasi, Jadwal Laboratorium, News, Struktur Organisasi.

\section{B. Design}

Tahapan selanjutnya adalah penulis akan membuat perancangan desain sistem dan selanjutnya akan membuat desain tampilan atau interface.

1. Use Case Diagram Manual.

Dalam tahapan awal penulis membuat desain sistem use case diagram manual yang berguna untuk mengetahui alur sistem sebelum adanya sistem yang terkomputerisasi. Seperti gambar 6 tahapannya adalah sebagai berikut:

a. User atau dalam selanjutnya disebut pengguna akan mencari informasi

b. Laboratorium akan memberikan informasi yang pengguna butuhkan. 


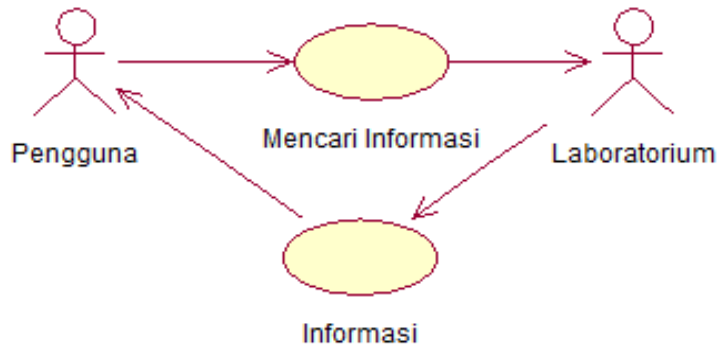

Gambar 6. $\quad$ Use Case Diagram Manual

2. Use Case Diagram Komputerisasi.

Pada tahapan selanjutnya adalah membuat desain sistem use case diagram komputerisasi, desain ini dibuat untuk mengetahui bagaimana sistem setelah terjadinya proses komputerisasi. Seperti pada gambar 7 tahapannya adalah sebagai berikut:

a. Teknisi atau yang selanjutnya disebut pengelola Laboratorium akan memilih menu login dan kemudian memilih pilihan update informasi

b. Selanjutnya jika berhasil akan melakukan proses isi data, dan selanjutnya menyimpan ke dalam database. Secara bersamaan data yang disimpan akan dimunculkan kedalam info.

c. Pada tahapan selanjutnya pengguna memilih pilihan menu.

d. Setelah pengguna memilih menu maka terakhir akan dimunculkannya informasi sesuai dengan apa yang dibutuhkan

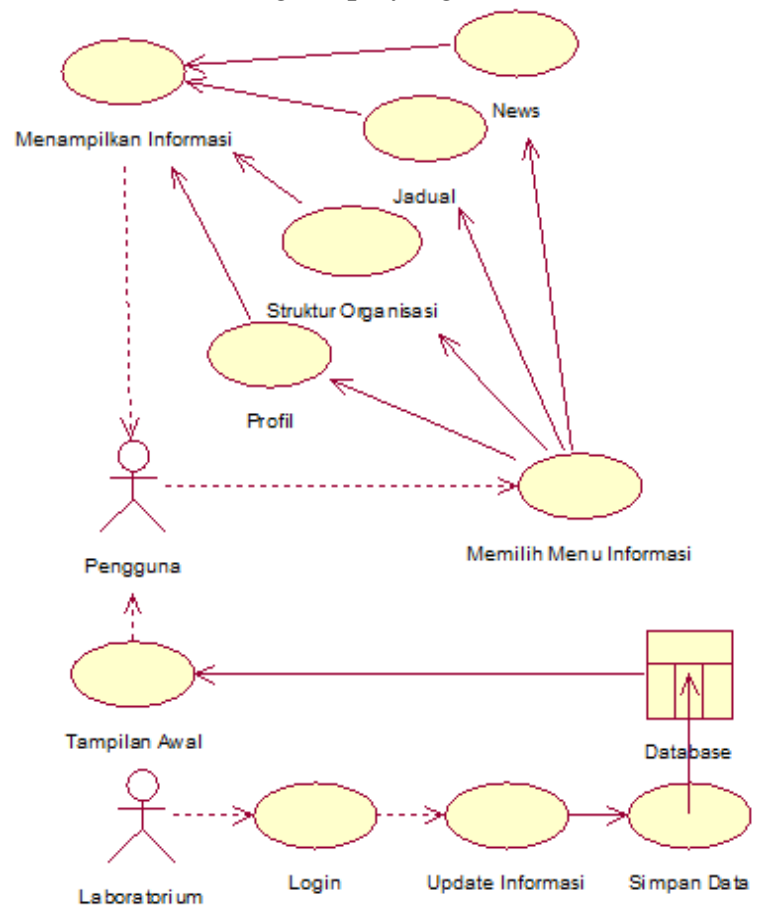

Gambar 7. Use Case Diagram Komputerisasi

\section{Class Diagram}

Dalam pembuatan aplikasi mobile informasi tagihan pelanggan Perusahaan Daerah Air Minum, penulis hanya menggunakan satu database dengan satu tabel. Tabel pengguna seperti pada gambar 8 mempunyai attribute antara lain no_ID (sebagai primary key) dan. Di dalam tabel ini juga mempunyai beberapa operasi yang dapat dilakukan, antara lain adalah operasi tambah data, hapus data dan juga perbarui.

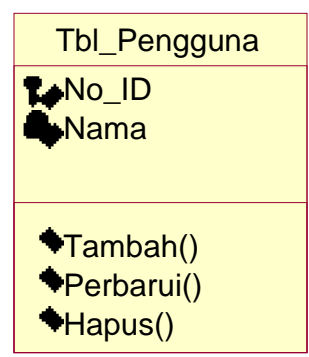

Gambar 8. Class Diagram

4. Desain Interface

Pada tahapan selanjutnya penulis akan membuat desain interface, desain ini yang nantinya digunakan sebagai panduan dalam pembuatan aplikasi. Pada tahap ini diantaranya penulis akan membuat desain form utama seperti pada gambar 9

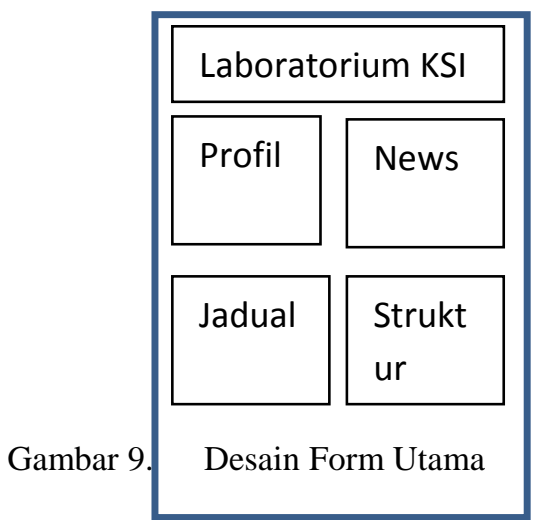

\section{Implementation}

Setelah membuat desain sistem maupun desain interface maka selanjutnya penulis akan melakukan pengkodean sesuai dengan desain yang telah dibuat. Pengkodean dibuat menggunakan bahasa pemrograman java. Pada tahap ini ada cuplikan kode untuk form login :

public class GLogin extends Activity \{ private Button btnLogin; private Button btnCancel; private EditText txtUsername; 
Dwi Putro S, Java Android Untuk Sarana Informasi Laboratorium Komputasi Dan Sistem Informasi

private EditText txtPassword; private TextView result; @Override public void onCreate(Bundle savedInstanceState) \{

super.onCreate(savedInstanceState); setContentView(R.layout.login);

txtUsername $=($ EditText $)$ findViewById(R.id.txtUser name);

txtPassword $=($ EditText $)$ findViewById(R.id.txtPass word);

btnLogin=(Button)findViewById(R.id.btnLogin);

btnCancel=(Button)findViewById(R.id.btnCancel); result $=($ TextView $)$ findViewById(R.id.result $)$;

D. Verification

Tahapan selanjutnya adalah tahapan verifikasi aplikasi dengan menjalankannya ke dalam telepon seluler berbasis android 2.2. Penulis telah melakukan percobaan aplikasi dan mempunyai hasil seperti pada gambar 10 yang merupakan salah satu pengujian menu informasi dari aplikasi.

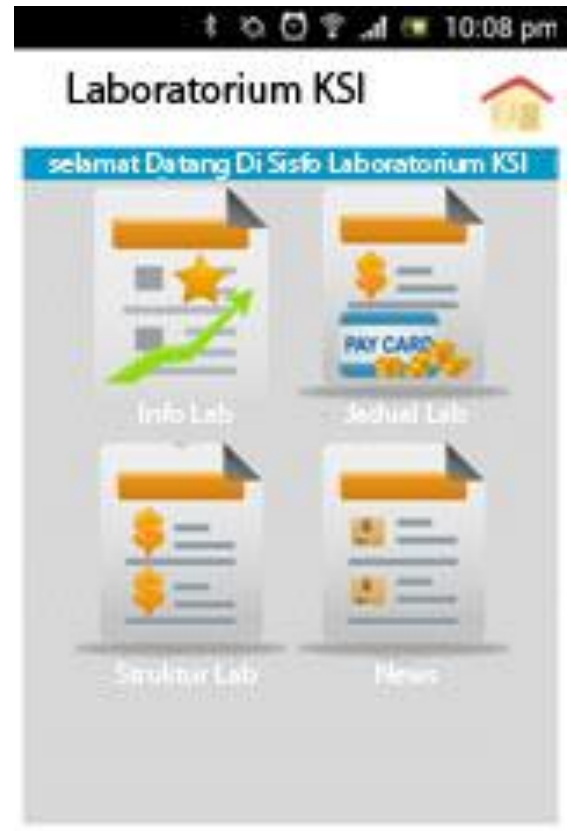

Gambar 10. Gambar Menu Informasi

\section{E. Maintenance}

Pada tahapan ini adalah tahapan untuk perawatan sistem. Namun demikian hingga saat ini perawatan belum dilakukan karena tidak menemui kendala serius pada perlakuan terhadap aplikasi yang ada. Perawatan disini lebih kepada update data yang ada.

\section{HASIL DAN PEMBAHASAN}

\section{A. Requirment}

Data - data yang dibutuhkan dikumpulkan dan di kelompokkan sesuai dengan kebutuhan sistem yang akan di bangun, diantaranya data Laboratorium Komputasi dan Sistem Informasi, Jadwal Laboratorium, dan Struktur Organisasi. Untuk sesi News merupakan capaian dari input terhadap apa yang akan disampaikan, jadi tidak ada data yang menjadi dasar. Salah satu kebutuhan data yang paling mendasar adalah data jadwal LAB.KSI yang dapat dilihat pada table 1 di bawah ini.

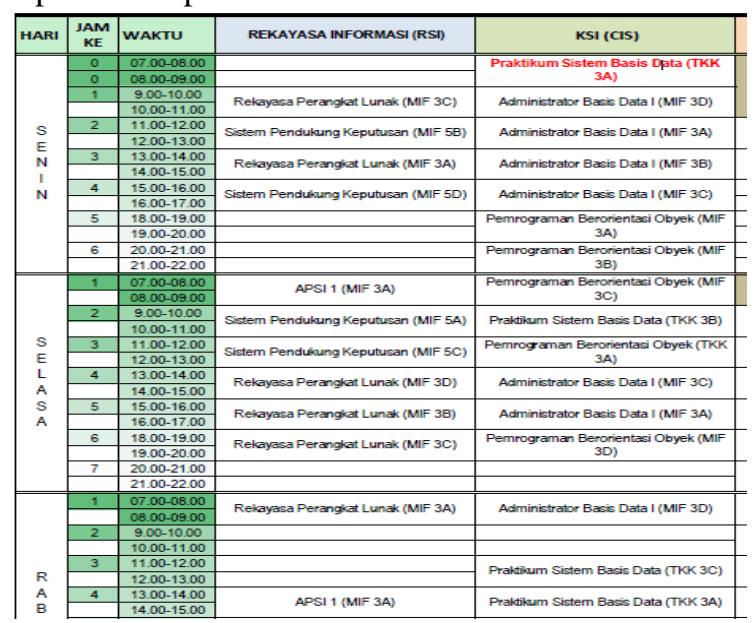

Tabel 1 Jadwal KSI untuk semester gasal $2011 / 2012$

\section{B. Design}

Pada tahapan ini, menggambarkan runtutan proses kerja dari sistem yang dibuat, baik design aliran data maupun interface nya.

1. Use Case Manual

Sebelum memulai mendesign sistem komputerisasi, data manual adalah dasar untuk mengembangkan design terkomputerisasi.

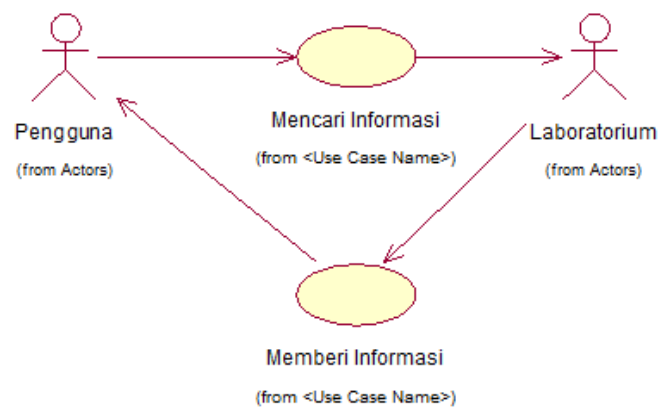

Gambar 11. Use Case Manual 
2. Use Case Komputerisasi

Bahwa Calon Pengguna Laboratorium untuk mengetahui informasi yang dibutuhkan hanya dengan menggunakan alat gadget dengan sistem operasi Android yang terhubung dalam jaringan lokal.

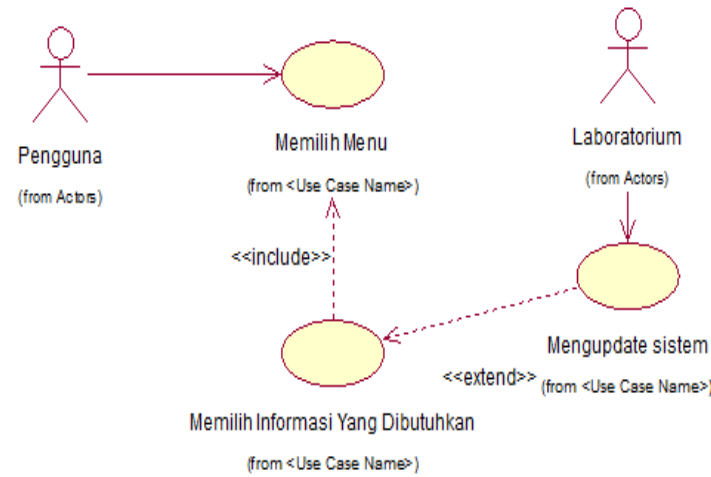

Gambar 12. Use case Terkomputerisasi

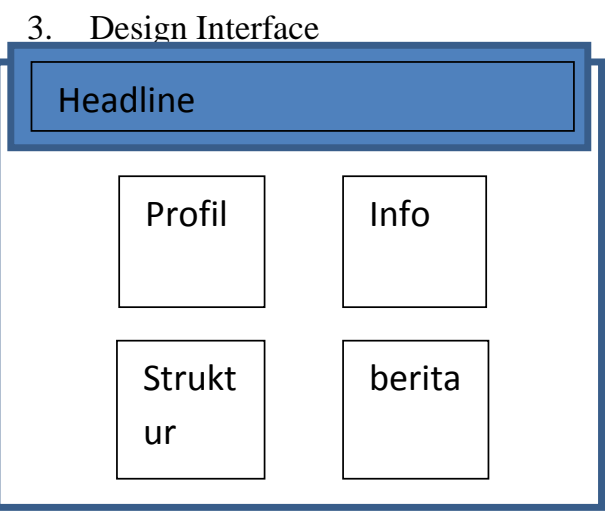

Gambar 13. Design Interface

Gambar 13 adalah design interface yang kemudian akan menjadikan dasar pembuatan interface yang sebenarnya. Headline adalah judul dari halaman, Profil adalah pilihan dimana pengguna akan mendapatkan informasi tentang profil Laboratorium, Info adalah pilihan dimana pengguna akan mendapatkan informasi tentang Jadwal Laboratorium, Struktur adalah terkait dengan informasi struktur organisasi, dan terakhir mengenai Berita yang akan di upload sesuai dengan informasi yang terbaru seputar Laboratorium.

\section{Implementation}

Setelah tahapan design dilanjutkan tahap implementasi. Dimana tahapan ini adalah mentransfer design kedalam bentuk coding yang mengasilkan sebuah sistem yang diharapkan berjalan sesuai dengan design yang telah dibuat.

1. Coding Halaman Utama

Gambar 14. Coding Potongan Koneksi dan halaman Utama

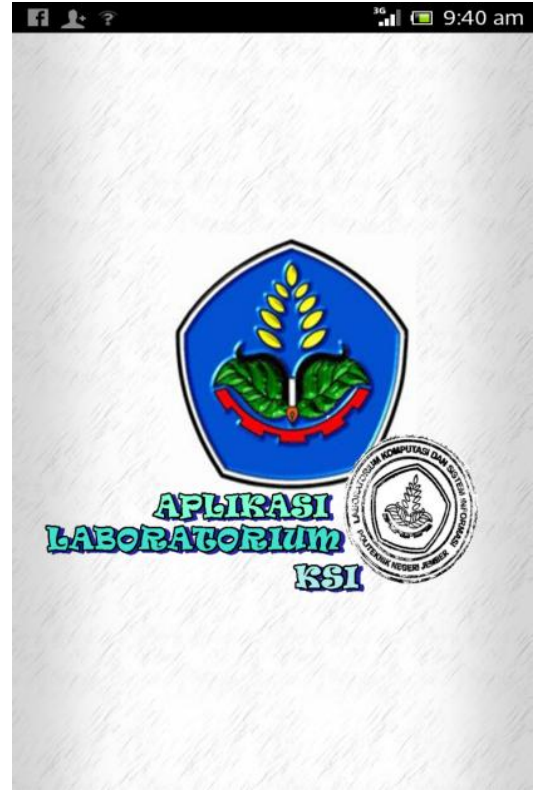

Gambar 15. Hasil Coding Halaman Utama

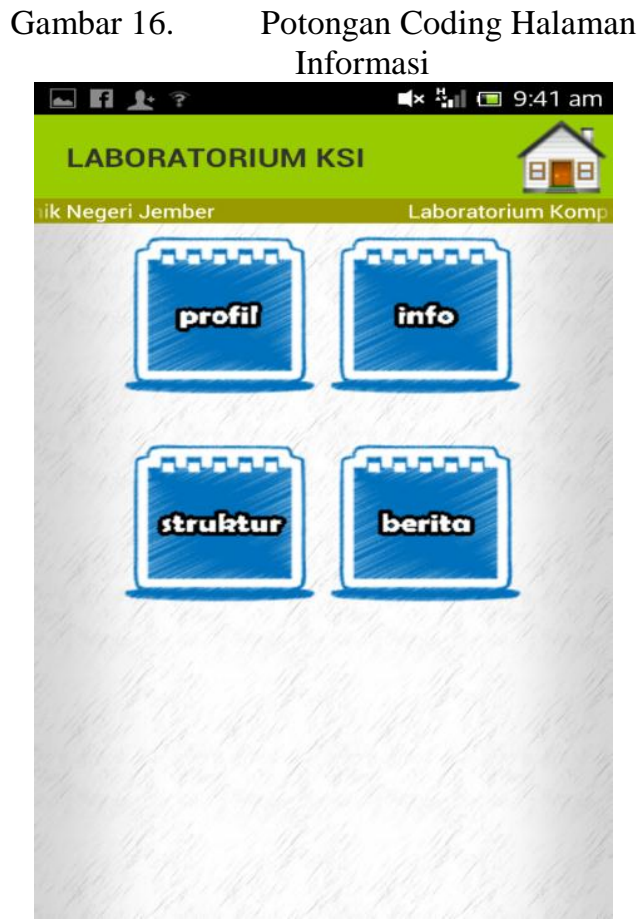

Gambar 17. Hasil Coding Halaman Menu Informasi

Gambar 18.

Pada Gambar 17, adalah sekilas tentang implementasi menu pilihan dari sistem yang dibuat. Di dalam menu tersebut ada opsi-opsi diantaranya Profil, Info, Struktur dan Berita. Untuk Update isi 
Dwi Putro S, Java Android Untuk Sarana Informasi Laboratorium Komputasi Dan Sistem Informasi

dari menu-menu yang ada, diupdate langsung melalui data base mysql.

2. Coding Halaman Info ( Jadual )
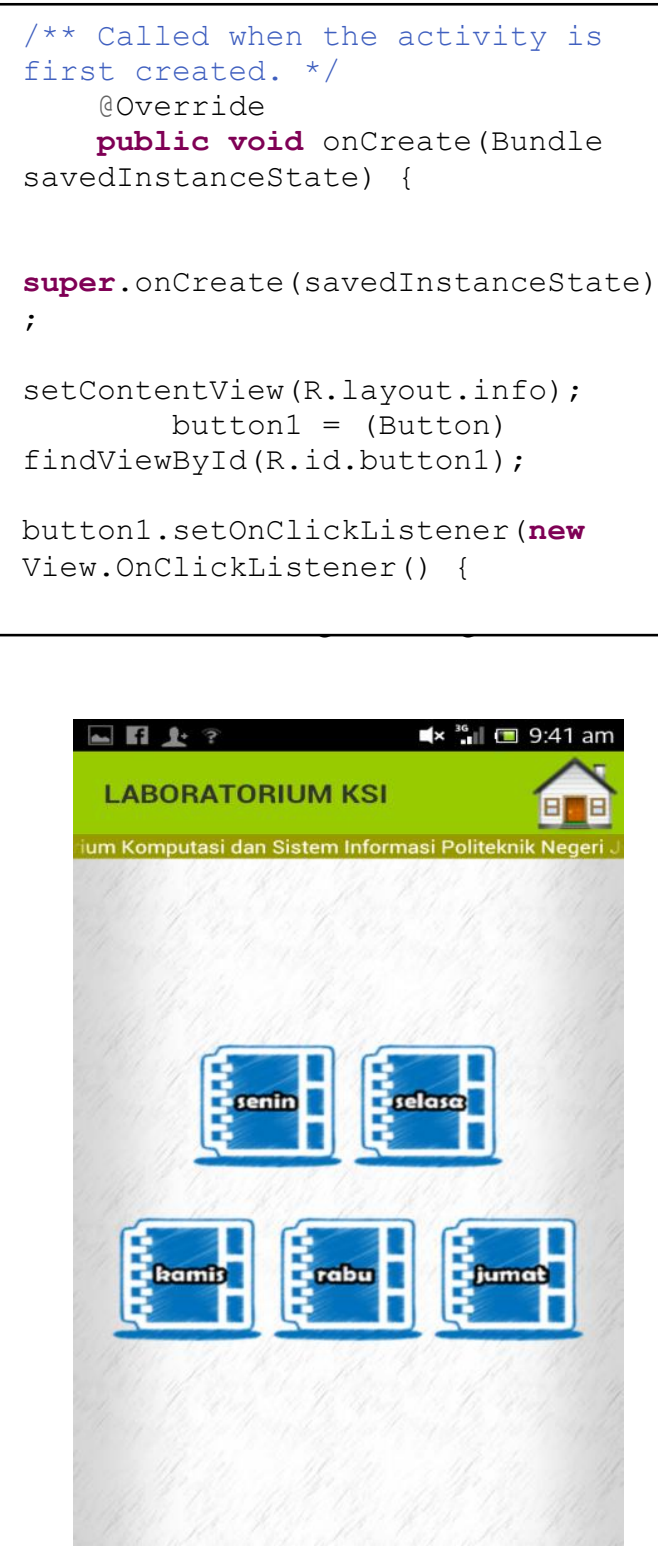

Gambar 20. Hasil Coding Halaman Jadual

\section{Verification}

Tahapan ini, mengaplikasikannya pada device berbasis android 4.0 ( Ice Cream Sandwich ). Dengan meng-copy kan file ber ekstensi .apk, kemudian dirunning langsung dari device tersebut otomatis sistem akan terinstalasi kedalam device.

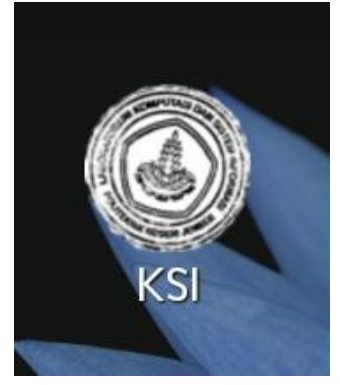

Gambar 21. Icon Aplikasi Yang Terinstall

\section{E. Maintenance}

Perawatan dalam tahap ini lebih kepada update database agar informasi yang disajikan tetap up to date. untuk keperluan maintenance sistem secara menyeluruh belum diperlukan.

\section{KESIMPULAN}

A. Kesimpulan

Dengan dibuatnya Java Android Untuk Sarana Informasi Laboratorium Komputasi Dan Sistem Informasi, maka dapat disimpulkan bahwa : 1. Dapat membantu dalam mencari informasi tentang Jadual Laboratorium 2. Dapat mengoptimalkan sarpras yang ada, baik dari jaringan wireless yang tersedia 3. Dapat mengoptimalkan penggunaan device berbasis android

\subsection{Saran}

Untuk mendapatkan informasi yang lebih fleksibel, untuk co-location database server bisa di letakkan pada dns parent polije, sehingga cakupan aksesnya bisa lebih luas tidak hanya pada sekitar laboratorium yang bersangkutan.

\section{DAFTAR PUSTAKA}

Dharwiyanti, S, dan R. S. Wahono. 2003. Pengantar Unified Modeling Language (UML). Kuliah umum IlmuKomputer.com.

Safaat H, N. 2011. Pemrograman Aplikasi Mobile Smartphone dan Tablet PC Berbasis Android. Bandung : Informatika.

Sommerville, I. 2003. Software Engineering (Rekayasa Perangkat Lunak)/Edisi 6/Jilid 1. Jakarta : Erlangga

Friesen, J. 2010. Learn Java for Android Deve 
Jurnal Ilmiah INOVASI, Vol.13 No.1, Januari -April 2013, Hal. 31-37, ISSN 1411-5549 